\title{
Development and validation of a questionnaire to measure asthma control
}

\author{
E.F. Juniper*, P.M. O’Byrne ${ }^{+}$, G.H. Guyatt* ${ }^{+}$, P.J. Ferrie*, D.R. King*
}

Development and validation of a questionnaire to measure asthma control. E.F. Juniper, P.M. O'Byrne, G.H. Guyatt, P.J. Ferrie, D.R. King. (C)ERS Journals Ltd 1999.

ABSTRACT: International guidelines on asthma management indicate that the primary goal of treatment should be optimum asthma control. The aim of this study was to develop and validate the Asthma Control Questionnaire (ACQ).

The authors generated a list of all symptoms used to assess control and sent it to 100 asthma clinicians who were members of guidelines committees (18 countries). They scored each symptom for its importance in evaluating asthma control. From the 91 responses, the five highest scoring symptoms were selected for the ACQ. In addition, there is one question on $\beta_{2}$-agonist use and another on airway calibre (total questions=7). The ACQ was tested in a 9-week observational study of 50 adults with symptomatic asthma. The ACQ and other measures of asthma health status were assessed at baseline, 1,5 and 9 weeks.

In patients whose asthma was stable between clinic visits, reliability of the ACQ was high (intraclass correlation coefficient $(\mathrm{ICC})=0.90)$. The questionnaire was very responsive to change in asthma control $(\mathbf{p}<\mathbf{0 . 0 0 0 1})$. Cross-sectional and longitudinal validity were supported by correlations between the ACQ and other measures of asthma health status being close to a priori predictions.

In conclusion, the Asthma Control Questionnaire has strong evaluative and discriminative properties and can be used with confidence to measure asthma control. Eur Respir J 1999; 14: 902-907.

International guidelines indicate that the primary goal of asthma treatment is to achieve optimum control (minimization of day and night time symptoms, bronchoconstriction and short-acting $\beta$-agonist use) and thus reduce the risk of life-threatening exacerbations and long-term morbidity [1-4]. CockCroft and Swystun [5] have pointed out that asthma "control" concerns the adequacy of treatment, whilst "severity" concerns the underlying disease process: "the common perception that well-controlled asthma is synonymous with mild asthma and that poorly controlled asthma is synonymous with severe asthma is erroneous".

A number of questionnaires are described as measuring "asthma severity". In some, the term "severity" has been used appropriately $[6,7]$ and the instruments validated against other measures of airway pathology. No questionnaires have been specifically developed and validated to measure asthma control. Without such an instrument, a simple, quantified method for identifying patients at risk and for evaluating the effects of treatment has been lacking.

The authors developed the Asthma Control Questionnaire (ACQ) using recognized procedures for questionnaire specification, item selection and scaling [8] and the authors have examined the measurement properties necessary for its use in clinical practice, clinical trials and cross-sectional surveys [9]. The aim was to develop a simple questionnaire that could be completed in the clinic without daily recordings of symptoms, medication use and airway calibre.
*Depts of Clinical Epidemiology and Biostatistics ${ }^{+}$Medicine, McMaster University Faculty of Health Sciences, Hamilton, Ontario, Canada.

Correspondence: E. Juniper, Dept of Clinical Epidemiology and Biostatistics, McMaster University Medical Centre, 1200 Main Street West, Hamilton, Ontario L8N 3Z5, Canada, Fax: 9055770017

\section{Keywords: Asthma measurement} questionnaire

Received: November 231998 Accepted after revision May 231999

Supported through a grant from Glaxo Wellcome Inc.

\section{Development}

\section{Questionnaire specifications}

The authors defined asthma control as: "the full range of clinical impairment that patients with asthma may experience as a result of their disease. The range is from 'well controlled', in which the patient is totally unimpaired and unlimited (this may be achieved either spontaneously, as in seasonal asthma, or by the use of medications) to 'extremely poorly controlled', which is a 'life-threatening state'.

It was specified that the ACQ should: 1) Include symptoms that asthma clinicians consider to be most important for assessing adequacy of asthma control. 2) Include a measure of a) short-acting $\beta_{2}$-agonist use and b) airway calibre. 3) Be applicable to all adults with asthma (17-70 yrs). 4) Be reliable (give reproducible data when the clinical state is stable and be able to discriminate between patients with different levels of asthma control). 5) Be responsive (be sensitive to small but clinically important changes in asthma control). 6 ) Be valid (actually measure asthma control). 7) Be short and easy to complete.

\section{Item generation phase}

The authors generated a list of all symptoms that might be used by clinicians to assess the adequacy of asthma control by identifying treatment goals from international 
Table 1. - Item reduction phase: highest scoring items

\begin{tabular}{|c|c|c|c|c|c|}
\hline \multirow[b]{2}{*}{ Symptom } & \multicolumn{5}{|c|}{ Frequency (number of clinicians scoring each category) } \\
\hline & $\begin{array}{l}\text { Extremely } \\
\text { important }\end{array}$ & $\begin{array}{c}\text { Very } \\
\text { important }\end{array}$ & $\begin{array}{c}\text { Moderately } \\
\text { important }\end{array}$ & $\begin{array}{l}\text { Not very } \\
\text { important }\end{array}$ & Useless \\
\hline Awoken at night by symptoms & 76 & 7 & 2 & 1 & 1 \\
\hline Limitation of normal daily activities & 67 & 12 & 4 & 3 & 1 \\
\hline Waking in the mornings with symptoms & 54 & 22 & 9 & 1 & 1 \\
\hline Dyspnoea & 31 & 39 & 15 & 1 & 1 \\
\hline Wheeze & 22 & 33 & 24 & 6 & 1 \\
\hline Cough & 13 & 37 & 28 & 5 & 3 \\
\hline Chest discomfort & 5 & 29 & 35 & 14 & 2 \\
\hline Sputum & 4 & 10 & 32 & 31 & 9 \\
\hline Coloured sputum & 1 & 7 & 28 & 31 & 19 \\
\hline Need to clear throat & 1 & 2 & 5 & 21 & 57 \\
\hline
\end{tabular}

The first five symptoms were included in the Asthma Control Questionnaire ( $\mathrm{n}=87 ; 4$ clinians failed to respond to this question).

guidelines $[1-3,10]$, reviewing other asthma questionnaires and talking to asthma clinicians. Ten potentially important symptoms were identified (tables 1, 2).

\section{Item reduction phase}

Subjects and methods. One hundred asthma clinicians, representing 18 countries, were asked to participate. They were clinicians who had served on international asthma guidelines committees [1-3, 10], asthma clinicians with measurement expertise and other opinion leaders in asthma management. Each clinician was sent a list of the 10 symptoms and asked both to score $(5=$ extremely important, $0=$ useless) and rank each symptom for its importance in evaluating asthma control. Participants were told that questions concerning airway calibre and short-acting $\beta_{2}$-agonists use would be included in the final questionnaire. They were asked to select the measure of airway calibre.

Results. Ninety-one clinicians returned the questionnaire. Importance and ranking of the 10 symptoms are shown in tables 1 and 2. Seventy-four per cent of respondents preferred prebronchodilator forced expiratory volume in one second (FEV1) \% predicted as the measure of airway calibre.

Asthma control questionnaire.. The ACQ includes the five highest scoring symptoms, one question about $\beta_{2^{-}}$ agonist use and another about FEV1, the latter being completed by the clinic staff. Patients recall their experiences during the previous 7 days and respond to each question using a 7-point scale (see Appendix). The items are equally weighted and the ACQ score is the mean of the 7 items and therefore between 0 (well controlled) and 6 (extremely poorly controlled).

\section{Validation study}

Subjects

Fifty adults (17-70 yrs) were enrolled from previous studies, local media notices and asthma clinics. They were required to have symptomatic asthma with an ACQ score $>0.5$ at enrolment. Patients were excluded if they had evidence of chronic obstructive pulmonary disease, an illness with symptoms similar to those of asthma (e.g. cardiac), recurrent chest infections, or were unable to communicate in English. The study was approved by the McMaster University Faculty of Health Sciences Ethics Committee. All patients signed an informed consent form.

\section{Study design}

In this 9-week, observational study, patients were seen in the clinic at enrolment and after 1, 5 and 9 weeks. At each visit, spirometry was measured before and $20 \mathrm{~min}$ after bronchodilator, and patients completed the ACQ. For validation purposes, patients also, completed the Asthma

Table 2. - Item reduction phase: highest ranking items

\begin{tabular}{|c|c|c|c|c|c|c|c|c|c|c|}
\hline & \multicolumn{10}{|c|}{ Number of clinicians in each rank* } \\
\hline & 1 & 2 & 3 & 4 & 5 & 6 & 7 & 8 & 9 & 10 \\
\hline Awaken at night by symptoms & 38 & 26 & 9 & 6 & 3 & 1 & 1 & 1 & 1 & 1 \\
\hline Limitation of normal daily activities & 21 & 14 & 25 & 11 & 4 & 3 & 5 & 2 & 1 & 0 \\
\hline Waking in the morning with symptoms & 6 & 25 & 23 & 11 & 7 & 8 & 5 & 0 & 1 & 0 \\
\hline Dyspnoea & 14 & 8 & 13 & 27 & 10 & 11 & 2 & 0 & 0 & 1 \\
\hline Wheeze & 7 & 9 & 4 & 12 & 24 & 17 & 7 & 4 & 1 & 1 \\
\hline Cough & 3 & 5 & 6 & 8 & 17 & 16 & 24 & 3 & 4 & 0 \\
\hline Chest discomfort & 1 & 3 & 5 & 13 & 12 & 19 & 20 & 3 & 7 & 1 \\
\hline Sputum & 0 & 1 & 2 & 2 & 2 & 2 & 14 & 41 & 18 & 2 \\
\hline Coloured sputum & 0 & 1 & 1 & 2 & 1 & 3 & 8 & 15 & 40 & 11 \\
\hline Need to clear throat & 2 & 0 & 0 & 1 & 0 & 0 & 1 & 8 & 7 & 63 \\
\hline
\end{tabular}

The first five symptoms were included in the Asthma Control Questionnaire (not all clinicans included all symptoms in their ranking). *: rank order of importance is, $1=$ most important, $10=$ least important. 
Table 3. - Longitudinal validity

\begin{tabular}{lc}
\hline & $\begin{array}{c}\Delta \text { Asthma Control } \\
\text { Questionnaire }\end{array}$ \\
\hline$\Delta$ Asthma Quality of Life Questionnaire & 0.73 \\
Overall & 0.73 \\
Symptoms & 0.57 \\
Emotions & 0.62 \\
Activities & 0.44 \\
Environment & \\
$\Delta$ Generic health status (SF-36) & 0.15 \\
Physical & 0.18 \\
Mental & 0.40 \\
Other asthma symptoms & 0.67 \\
Global rating of change & \\
\hline
\end{tabular}

Data are presented as Pearson correlation coefficients. A priori predictions: 1) Change in Asthma Quality of Life Questionnaire: $r=0.4-0.8$; the highest correlations should be with the symptom domain $(\mathrm{r}=0.6-0.8)$ and the lowest with the environmental domain ( $\mathrm{r}=0.4-0.6)$. 2) Change in "the physical health" domain of the Medical Outcomes Survey Short Form-36 (SF36): $\mathrm{r}=0.2-0.4$. 3) Change in the 5 additional asthma symptoms (cough, chest tightness, sputum, coloured sputum and clearing the throat): $r=0.4-0.6$. 4) Clinician's global rating of change: $r>0.6 . \Delta$ : mean change.

Quality of Life Questionnaire (AQLQ) [11] and the Medical Outcomes Survey Short Form-36 (SF-36) [12] and scored the five least important asthma symptoms (table 1), responding to each question on a 7-point scale. For one week before each follow-up visit, patients recorded prebronchodilator peak expiratory flow (PEF) each morning and daily use of short-acting $\beta_{2}$-agonist. At each follow-up visit, a clinician rated change in the patient's asthma control since the previous clinic visit $(+7=$ a very great deal better, $0=$ no change, $-7=$ a very great deal worse) [13]. The clinician was blinded to the ACQ data and used only spirometry, diary, AQLQ and SF-36 data plus a consultation with the patient.

Medications. Patients whose asthma was adequately controlled continued on their established asthma medications throughout the study. Patients whose asthma was not adequately controlled at week 1 and/or week 5 were advised to increase their medication as recommended by their asthma physician.

\section{Testing the measurement properties}

General approach. A health status instrument that is required to measure change over time (e.g. clinical trials and clinical practice) must have good evaluative properties which are responsiveness (the ability to detect important within-patient changes, even if they are small) and longitudinal construct validity (appropriate correlations between changes in the new instrument and changes in established health status measures) [9]. An instrument that is required to distinguish between people at a single point in time (e.g. surveys and impairment assessment) must have good discriminative properties which are reliability (high ratio of variance between-patients to variance within-patients) and cross-sectional construct validity (appropriate correlations between established measures and the new instrument) [9]. The ACQ was tested for both evaluative and discriminative properties.

\section{Statistical analysis}

Categorizing patients. Conceptually, testing the ACQ's measurement properties required defining a group of patients who remained clinically stable between consecutive clinic visits (weeks 1-5 and 5-9) and another group who experienced change in their asthma control. For each time period, each patient was categorized using the clinician's global rating of change: stable group $=$ scores of $-1,0$ or +1 ; unstable group $=$ scores $-7--2$ and $+2-$ $+7[13]$.

Evaluative properties. Responsiveness of the ACQ was examined in three ways. Firstly, for patients in the unstable group, it was determined whether the ACQ could detect within-patient change using a paired t-test. Secondly, it was assessed whether the ACQ could detect differences between stable and unstable patients using an unpaired t-test. Thirdly, the responsiveness index (mean change $(\Delta)$ /standard deviation of change $(\operatorname{SD} \Delta)$ was calculated [14]. To ensure that the contribution of two observations by some patients did not result in an overestimate of the precision of responsiveness, the authors inflated the variance by the quantity $1+(n-1) \rho$ where $\rho$ is the intraclass correlation coefficient (ICC) of the change scores and $\mathrm{n}=2$ (No. of observations per subject) [15]. For longitudinal validity, a priori predications were made about the amount of correlations that should be expected to be observed if the ACQ truly measures change in asthma control. The predictions were based on results from previous studies and clinical experience.

Discriminative properties. Reliability of the ACQ was determined from patients in the stable group. If a patient was stable between both weeks $1-5$ and weeks $5-9$, a single observation was selected using a random number generator. Reliability was estimated as the within-subject standard deviation and related to the total standard deviation as an ICC. For cross-sectional validity, data from the second clinic visit (week 1) were used and once again a priori predications were made about the level of correlation that should be expected if the ACQ truly measures asthma control.

\section{Results}

All fifty patients (18 males, 32 females) completed the study. Their mean age was $37 \pm 13$ (SD) yrs and pre-bronchodilator FEV1 \% pred. was $77.2 \pm 18.8$. Twelve patients used short-acting $\beta_{2}$-agonists alone; 34 needed regular inhaled steroids plus short-acting $\beta_{2}$-agonists; three took inhaled steroids plus both long and short-acting $\beta_{2}$-agonists; and one required all three medications plus an oral steroid.

\section{Evaluative properties}

Thirty-six patients contributed 50 observations to the unstable group. Symmetry of improvements $(n=26)$ and deteriorations $(\mathrm{n}=24)$ allowed the combination of the data by changing the sign of those who deteriorated. The ACQ was able to detect change in these patients (mean change $0.73 \pm 0.54, p<0.0001)$. There was minimal change in the stable group (mean change $0.01 \pm 0.24, \mathrm{p}>0.05$ ) and the ACQ was able to detect the difference between the stable 
and unstable groups $(\mathrm{p}<0.0001)$. The responsiveness index was 1.35. Correlations between changes in the ACQ and changes in other measures, in general, agreed well with $a$ priori predictions (table 3 ).

\section{Discriminative properties}

Thirty-six patients contributed 50 observations to the stable group, within-subject SD was 0.18 with an ICC of 0.90 . Correlations between the ACQ and the other outcome measures matched the a priori predictions quite well (table 4).

\section{Discussion}

Although there is a plethora of asthma symptom questionnaires, this is the first to be specifically developed and validated to measure asthma control. The authors first examined the goals of asthma treatment $[1-3,10]$ and then sought consensus from international opinion leaders concerning the symptoms and measures of airway calibre that are most important for assessing asthma control. Agreement was sufficiently high for the authors to have confidence in selecting the top scoring items for the ACQ.

The technique used to develop the ACQ is unique in that a large number of leading asthma clinicians from around the world participated in identifying the questions that should be included. The authors interpret the high response rate as an indication of the importance they place upon this instrument to help disseminate the concept and goals of optimum asthma management. The high level of consensus among clinicians removes any ambiguities that may have existed concerning the meaning of optimum asthma control.

This study has shown that the ACQ has strong measurement properties both as an evaluative and as a discriminative instrument and can be used with confidence in both clinical trials and cross-sectional surveys. The ACQ is needed for research studies to measure the primary goal of asthma treatment, to identify populations at risk and to facilitate comparison of results across studies.

Table 4. - Cross-sectional validity

\begin{tabular}{lc}
\hline & $\begin{array}{c}\text { Asthma control } \\
\text { questionnaire }\end{array}$ \\
\hline $\begin{array}{l}\text { Asthma Quality of Life Questionnaire } \\
\text { (AQLQ) }\end{array}$ & 0.76 \\
Overall & 0.75 \\
Symptoms & 0.66 \\
Emotions & 0.71 \\
Activities & 0.55 \\
Environment & 0.55 \\
Generic Health Status (SF-36) & 0.19 \\
Physical & 0.42 \\
Mental & \\
Other Asthma Symptoms & \\
\hline Data are presented as Pearson correlation coefficients. $A$ priori \\
predictions: 1 ) AQLQ: $\mathrm{r}=0.4-0.8$. The highest correction should \\
be with the symptom domain (r=0.6-0.8) and the lowest with \\
the environment domain (r=0.4-0.6). 2) "physical health" do- \\
main of the Medical Outcomes Survey Short Form-36 (SF-36): \\
r=0.4-0.6. 3). The five additional asthma control symptoms: \\
r=0.4-0.6.
\end{tabular}

To meet the authors' specifications of brevity and completion in the clinic, the ACQ includes only those symptoms that most commonly reveal lack of control in the majority of patients and does not include daily PEF measurement. Nevertheless, it is believed that there is an important role for the ACQ in the management of individual patients in both general practice and tertiary care. Not only does the ACQ allow clinicians to become familiar with the goals of asthma management, but it can also identify patients with poor control and, more accurately than recall, evaluate the effects of interventions. In addition, completion of the ACQ in the waiting room may save consultation time and group monitoring may be used to enhance disease management and thus reduce resource utilization.

For categorizing patients into the stable and unstable groups, it would have been ideal for several clinicians, blinded to the ACQ data, to have independently assessed each patient at each clinic visit and a consensus taken as to whether each patient had changed. This was not feasible and left the choice of reviewing recorded data at a later date for a group decision or having one clinician make the decision at the time of the clinic visit. The latter was selected because a group decision would have had to rely heavily on recorded symptoms, $\beta_{2}$-agonist use and airway calibre, i.e. all the data recorded in the ACQ. The approach taken makes it less likely that spuriously high correlations resulted from ACQ data exercising undue influence on the global rating.

A limitation of this study is the relatively small and possibly homogeneous sample. Although the authors endeavoured to enrol patients with a wide range of asthma severity and socioeconomic background, most were Caucasian. Testing of the Asthma Control Questionnaire in other settings will increase confidence in the general applicability of the results.

\footnotetext{
Acknowledgements. The authors thank the following clinicians who completed the item reduction questionnaire, many of whom also gave excellent suggestions: E. Adelroth, R. Antic, W.C. Bailey, N.C. Barnes, P.J. Barnes, R. Beasley, A.B. Becker, E. Bel, L-P. Boulet, J. Bousquet, R.A.L. Brewis, J.R. Britton, A.S. Buist, W.W. Busse, A. Cartier, K.R. Chapman, T.J.H. Clark, G.M. Cochrane, D.W. Cockcroft, G.K. Crompton, R. Dahl, R.J. Davies, J. Dolovich, S.R. Durham, D. Evans, J.M. Fitzgerald, P.G. Gibson, S. Godfrey, M. Gotz, F.E. Hargreave, B.D.W. Harrison, D.J. Hendrick, S.R. Hilton, T.W. Higenbottam, S.T. Holgate, W.F. Holmes, P.H. Howarth, G.H. Koeter, L.I. Landau, D.J. Lane, T.H. Lee, H. Levison, A.J. Lockhart, H. Magnussen, J-L. Malo, G.B. Marks, R.J. Martin, A.D. Milner, C. Mitchell, H.J. Neijens, H.S. Nelson, E. Neville, M.T. Newhouse, A.J. Newman-Taylor, R.L. Page, M.R. Partridge, R.A. Pauwels, M.G. Pearson, S. Pedersen, T.A.E. Platts-Mills, D.S. Postma, J.F. Price, H.H. Rea, C.E. Reed, R. Rodriguez-Roisin, A.R. Rubinfeld, M. Rudolf, R.E. Ruffin, G.F. Ryan, J.M. Samet, J.P. Seale, M.R. Sears, G.G. Shapiro, A.L. Sheffer, P. Sherwood Burge, M. Silverman, P.J. Sterk, A. Szczeklik, A.E. Tattersfield, N. Thomson, J.H. Toogood, E.H. Walters, J.O. Warner, S.T. Weiss, A.J. Woolcock, M. Yeung, P. Zimmerman.
} 


\section{ASTHMA CONTROL QUESTIONNAIRE $\mathbb{C}$}

Please answer questions 1-6.

Circle the number of the response that best describes how you have been during the past week

1. On average, during the past week, how often were you woken by your asthma during the night?

2. On average, during the past week, how bad were your asthma symptoms when you woke up in the morning?

3. In general, during the past week, how limited were you in your activities because of your asthma?

4. In general, during the past week, how much shortness of breath did you experience because of you asthma?

5. In general, during the past week, how much of the time did you wheeze?

6. On average, during the past week, how many puffs of short-acting bronchodilator (eg. Ventolin) have you used each day?

To be completed by a member of the clinic staff

7. FEV1 pre-bronchodilator:

FEV1 predicted

FEV1 \% predicted

(Record actual values on the dotted lines and score the FEV1 \% predicted in the next column)
Never

Hardly ever

A few minutes

Several times

Many times

A great many times

Unable to sleep because of asthma

No symptoms

Very mild symptoms

Mild symptoms

Moderate symptoms

Quite severe symptoms

Severe symptoms

Very severe symptoms

Not limited at all

Very slightly limited

Slightly limited

Moderately limited

Very limited

Extremely limited

Totally limited

None

A very little

A little

A moderate amount

Quite a lot

A great deal

A very great deal

Not at all

Hardly any of the time

A little of the time

A moderate amount of the time

A lot of the time

Most of the time

All the time

None

$1-2$ puffs most days

3-4 puffs most days

5-8 puffs most days

9-12 puffs most days

13-16 puffs most days

More than 16 puffs most days

(C) The Asthma Control Questionnaire is copyrighted. It may not be changed, translated or sold (paper or software) without the permission of Elizabeth Juniper. 


\section{References}

1. British Thoracic Society, Research Unit of the Royal College of Physicians of London, King's Fund Centre, National Asthma Campaign. Guidelines for management of asthma in adults: I chronic persistent asthma. $\mathrm{Br} \mathrm{Med} \mathrm{J}$ 1990; 301: 651-653.

2. US Department of Health Services. International Consensus Report on Diagnosis and Treatment of Asthma. Bethesda: National Heart, Lung, and Blood Institute, 1992.

3. Thoracic Society of Australia and New Zealand. Woolcock A, Rubinfeld AR, Seale JP, Landau LL, Antic R, Mitchell C, Rea HH, Zimmerman P. Asthma management plan 1989. Med J Aust 1989; 151: 650-653.

4. Ernst P, Fitzgerald JM, Spier S. Canadian asthma consensus conference: summary of recommendations. Can Respir J 1996; 3: 89-100.

5. Cockcroft DW, Swystun VA. Asthma control versus asthma severity. J Allergy Clin Immunol 1996; 98: 1016-1018.

6. Burney PGJ, Chinn S, Britton JR, Tattersfield AE, Papacosta AO. What symptoms predict the bronchial responsive to histamine? Evaluation in a community survey of the bronchial symptoms questionnaire (1984) of the international union against tuberculosis and lung disease. Int J Epidemiol 1989; 18: 165-173.

7. Venables KM, Farrer N, Sharp L, Graneek BJ, NewmanTaylor AJ. Respiratory symptoms questionnaire for asthma epidemiology; validity and reproducibility. Thorax 1993; 48: 214-219.

8. Juniper EF, Guyatt GH, Jaeschke R. How to develop and validate a new quality of life instrument. In: Spilker B. ed. Quality of Life and Pharmacoeconomics in Clinical Trials. Second Edition. Raven Press Ltd, New York, 1995; pp. 49-56.

9. Guyatt GH, Kirshner B, Jaeschke R. Measuring health status: what are the necessary measurement properties? $J$ Clin Epidemiol 1992; 45: 1341-1345.

10. Hargreave FE, Dolovich J, Newhouse MT. The assessment and treatment of asthma: a conference report. $J \mathrm{Al}$ lergy Clin Immunol 1990; 85: 1098-1111.

11. Juniper EF, Guyatt GH, Ferrie PJ, Griffith LE. Measuring quality of life in asthma. Am Rev Respir Dis 1993; 147: 832-838.

12. Bousquet J, Knani J, Dhivert $\mathrm{H}$, et al. Quality of life in asthma. 1. Internal consistency and validity of the SF-36 questionnaire. Am J Respir Crit Care Med 1994; 149: 371-375.

13. Juniper EF, Guyatt GH, Willan A, Griffith LE. Determining a minimal importafit change in a disease-specific quality of life instrument. J Clin Epidemiol 1994; 47: 8187.

14. Guyatt GH, Walter S, Norman G. Measuring change over time: assessing the usefulness of evaluative instruments. $J$ Clin Dis 1987; 40: 171-178.

15. Juniper EF, Guyatt GH, Feeny DH, Griffith LE, Ferrie PJ. Minimum skills required by children to complete healthrelated quality of life instruments: comparison of instruments for measuring asthma-specific quality of life. Eur Respir J 1997; 10: 2285-2294. 